\title{
La soledad enamorada 1
}

\author{
MARÍA ZAMBRANO \\ (1904-1996)
}

Si ha habido un hombre de muchas y contradictorias personalidades, desgarrado por la desbordante riqueza, por la punzante contradicción, es, sin duda, Nietzsche, tan amado y repudiado, tan olvidado y presente. Condenado en vida a la soledad más desolada, sus palabras han corrido la suerte tristísima de ser cogidas, diríamos por los pelos, y ateniéndose a la más muerta letra, por los peores, por aquellos que reúnen las condiciones que más le repugnaron, por aquellos que representan la voz de los suburbios humanos, allí donde jamás llegó la más leve claridad. Los que pretenden ser el superhombre simplemente, porque no llegan a ser hombres, y al rebelarse contra lo humano se nombran a sí mismos con la denominación de un «superhombre», que Nietzsche inventó en su más encendido amor por lo humano.

Nietzsche representa hoy, al cabo de su muerte, el calvario de la soledad apurada hasta lo último, sorbida con estoica crueldad, llevada hasta más allá de todo lindero visible. Tan solo se quedó, que en su camino acabó por marchar más allá de todo horizonte; allí donde ya no podía comunicarse con nadie, donde ninguna voz humana le podía lle-

1 Publicado por primera vez en la revista Universidad Michoacana, 16, julio 1939 (Morelia, México). Reeditado en La confesion: Género literario, Mondadori, Madrid, 1988, pp. 73-78, de donde ha sido tomado. Se publica aquí con la autorización de la Fundación «María Zambrano». 
gar. Desapareció en vida, separado de los hombres por una helada soledad, descansando quizá en el seno de la nada, en el seguro acogedor de un ensueño sin conciencia, él, que llegó a desgarrarla por tanta luz.

¡La soledad del intelectual que huye de los hombres! En Nietzsche está en toda su pureza y plenitud la situación que tanto se le ha reprochado al intelectual, la llamada «torre de marfil», que en él fue libre espacio en las más altas cumbres agrestes, alturas del planeta paralelas a las alturas de su espíritu. Y está más claramente que en ningún otro, porque lejos de pretender encubrir su soledad, hizo de ella una virtud, una fuerza de donde nacía su fuerza creadora. La condición inexcusable de toda grandeza humana.

Lagran fuerza atractiva de Nietzsche está en que pasó por el mundo arrancando máscaras. Amante de la verdad, descorriendo velos que hubo que rasgar muchas veces con toda violencia, con obstinada ironía. Arrancando máscaras y creándolas. Tal fue su destino. «Todo espíritu profundo necesita una máscara ${ }^{2}$. ¿Y no fue quizá su máscara la soledad? Máscara de algo que un pudor excesivo no le dejaba mostrar, máscara de su desesperación. La soledad le impidió tal vez el suicidio, pues convirtió en pasión una carencia, una mutilación de su vida. Fiel a sí mismo hasta la locura, aceptó su soledad, transformándola en virtud, en fuerza creadora. Pero ¿qué íntimo proceso, qué hondo calvario no tuvo que recorrer hasta sumergirse enteramente como un amor definitivo en su casta soledad de hombre pensante?

Nietzsche superó el suicidio, le atravesó, le traspasó a fuerza de aceptar con toda entereza su destino. Un destino que le aislaba de los hombres en ese momento. Porque el destino del hombre de tal condición, va más allá de su ser humano, de su corazón y de sus instintos, que se le convierten en instrumentos para el cumplimiento de tal destino. El destino de un hombre cae sobre él, pero no nace de él, no depende de él, sino que le sobrevive porque es cosa de la historia.

Cosas de la historia suelen ser las cosas más graves individuales. Y el yerro mayor del individualismo, tal vez el único, haya sido creer que el individuo puede aislarse de la historia, abstrayéndose de las circunstancias concretas que presiden con la inexorabilidad de los astros, su pobre vida. El creer, en suma, que la separación del individuo con res- 
pecto al medio y a la especie es absoluta. El creer que puede determinarse a sí mismo.

Tal error idealista no fue, naturalmente, compartido por Nietzsche, y no fue, por tanto, esa la razón de su soledad casi absoluta. La razón no era una idea, sino una realidad terrible; la realidad del tiempo y de la nación en que vivía.

En el reproche, justo en muchos casos, que se ha dirigido al intelectual por su sueño de pureza, libre del contacto de los hombres, se ha envuelto en situaciones bastante diferentes, lo suficientemente diferentes para que alguien intentara el discernimiento de ellas. La soledad tremenda de Nietzsche, la máscara de su soledad con que ocultaba su inmenso amor por la «regla» por aquello común en todos los hombres, a través de todas sus invectivas, nos alumbra un poco de esta cuestión. ¿Por qué la soledad de Nietzsche? ¿Quién le impidió vivir entre los hombres, mezclado a sus afanes y riesgos, participando del destino común? El acudir a las abundantes manifestaciones de desprecio por lo que él llama «la plebe y lo plebeyo», no nos serviría de mucho, pues se encontraría texto en que se manifiesta lo contrario, cuando se abandona; cuando aparece el poeta rasgando el mito de su pensamiento, cuando se ahoga y grita su verdad íntima en el amor tremendo, inmenso de lo humano. Lejos de los hombres acaba por soñarlos; acaba por soñar un hombre purificado, encendido de fuerza, con todo lo humano, que no prescinda de nada y sea encarnación de todo. Que sea tal que no haya ninguna idea que le sea superior; un hombre que desafíe y haga palidecer todos los ideales; que haga inútiles todas las normas morales, las caretas pobres en que lo humano se escondía, según él: el cristianismo, el puritanismo, el utilitarismo... porque él creía que el hombre era más que sus pretendidas definiciones y que toda moral era un empobrecimiento. Su amor a lo humano le hizo saltar por encima del bien y del mal, barreras que contienen la viva realidad del hombre: «Todo lo que se hace por amor, se hace más allá del bien y del mal». Y él no hizo otra cosa.

Todas las ideas morales le parecieron estrechas para el hombre. La realidad humana le inspiraba una fe que sobrepasaba a las ideas, a las normas. Los conceptos con que Nietzsche se sirviera para repudiar a las fuerzas limitadoras. «Haz tu corazón pequeño» pudieron ser y sin duda fueron equivocadas, pues al fin era un hombre de su tiempo y como tal oponía a las morales en uso otra inventada por él. La tradi- 
ción filosófica europea estaba demasiado penetrada de moralismo para que un filósofo, por genial que fuese, no viniese a participar de él, oponiendo a las morales que cubren la realidad del hombre otra suya en la cual transitoriamente se apoyaba.

No hubiera sucedido así si Nietzsche desde el primer momento hubiera tenido una intuición total del hombre. Pero no; el hombre se le va revelando precisamente en su soledad, a medida que deshace las máscaras morales, a medida que su sagacidad infatigable va escudriñando los rincones más ignorados y su audacia sin límites va analizando todo lo que parecía intangible y venerado. A medida que su soledad va llenándose de la imagen que su enamoramiento crea. Entonces lo que podríamos llamar su moral antigua, su moral de aislamiento salvaje, de desprecio a lo mediocre, de afán ilimitado de pureza, va palideciendo por la esplendente visión del hombre nuevo. Su distinción entre «moral de esclavos» $\mathrm{y}$ «moral de señores» va quedándose como lo que era: un instrumento para atacar a las morales al uso, un apoyo intelectual en su crítica, una base de su audacia.

Pero esta audacia, este afán desmedido de verdad y veracidad, este desenmascaramiento constante de todo, no hubiera existido de no estar aguijoneados por el amor más terrible, ardiente y decisivo. No habrían existido si Nietzsche no hubiera sido un enamorado.

Un enamorado de los hombres, de los hombres que no pudo convivir con ellos, porque su desmedido amor de una convivencia absoluta le disminuía cada vez más el número de seres con que tal exigente comunidad podía establecerse. Pero a más de esta exigencia amorosa, está el hecho social de que toda convivencia humana, hasta ahora, se ha sostenido en algo: en una moral común, en unas normas comunes, en unos dioses que se veneran juntos o en unos demonios a quienes se repudia al mismo tiempo. El hombre ha estado tan oculto para el hombre y tan lleno de temores, tan nublada su frente y mudo su corazón, que apenas se ha manifestado directamente ante otro hombre. Ha sido a través de ideas, de normas, de cultos cómo los hombres se han encontrado. En este sentido, toda sociedad ha sido en cierto modo y en cierta medida «idealista». A medida que el hombre tomaba conciencia de su realidad, la soledad individual se hacía más incomprensible y nacían los mártires de todas las luterodoxias. De su acumulación se engendraron las revoluciones, que ya no tendrán ra- 
zón de ser cuando el hombre se haya encontrado con su íntima realidad y pueda ser comunicada y serenamente contemplada por todos.

Nietzsche no alcanzó tan venturosos tiempos. En el suyo había unas ideas imperantes, rígidas ideas en la patria de las ideas, que le apartaban de toda comunicación, que le negaban aquello que su amor perseguía. En lugar de la viva realidad humana, encontraba las sólidas ideas, las vestiduras opacas, las torpes palabras. Tuvo que apartarse a solas con su amor. «No quiero enviarme hoy más mensajeros, que no saben decirme lo que quiero»3.

Las ideas al uso, las morales que encubrían la humana realidad, condenaron a Nietzsche a vivir en una soledad absoluta de donde no puede volver. Pero en su soledad de enamorado atacó sin tregua a todo lo que le separaba de la convivencia de los hombres. Amó sin tregua ni descanso por encima de sus propias ideas, de sus propias doctrinas. Tal fue su tragedia. ¿Podría culparse a un ser así de su aislamiento? ¿Tiene algo que ver con el individualismo idealista? ¿No es en realidad todo lo contrario del filósofo que se envuelve en sus abstracciones para alejarse de las cuestiones humanas, para aliviarse de la carga de la responsabilidad, para olvidarse de los hombres y sus conflictos? Pensamos que, en efecto, fue todo lo contrario; fue todo lo contrario de la soledad enamorada del hombre que representa la mayor tragedia humana: dar no la vida, la razón por amor; alejarse de lo único que se ama, de lo único que podría traernos la felicidad. Alejarse del pueblo, que es la materia única en que espera encarnar toda nobleza, toda grandeza. 